\title{
Reciprocal relationship between APP positioning relative to the membrane and PS1 conformation
}

\author{
Kengo Uemura ${ }^{2}$, Katherine C Farner ${ }^{1}$, Navine Nasser-Ghodsi ${ }^{1}$, Phill Jones ${ }^{1}$, Oksana Berezovska $^{1 *}$
}

\begin{abstract}
Background: Several familial Alzheimer disease (FAD) mutations within the transmembrane region of the amyloid precursor protein (APP) increase the $A \beta_{42 / 40}$ ratio without increasing total $A \beta$ production. In the present study, we analyzed the impact of FAD mutations and $\gamma$-secretase modulators (GSMs) that alter the A $\beta_{42 / 40}$ ratio on APP C-terminus $(\mathrm{CT})$ positioning relative to the membrane, reasoning that changes in the alignment of the APP intramembranous domain and presenilin 1 (PS1) may impact the PS1/ $\gamma$-secretase cleavage site on APP.

Results: By using a Förster resonance energy transfer (FRET)-based technique, fluorescent lifetime imaging microscopy (FLIM), we show that $A \beta_{42 / 40}$ ratio-modulating factors which target either APP substrate or PS1/ $\gamma$ secretase affect proximity of the APP-CT to the membrane and change PS1 conformation.

Conclusions: Thus, we propose that there is a reciprocal relationship between APP-CT positioning relative to the membrane and PS1 conformation, suggesting that factors that modulate either APP positioning in the membrane or PS1 conformation could be exploited therapeutically.
\end{abstract}

\section{Background}

$\gamma$-Secretase is responsible for cleavage of a number of type I membrane proteins, including amyloid precursor protein (APP) and Notch, and is comprised of presenilin 1 or 2, Aph1, Pen2 and Nicastrin [1-5]. Proteolytic processing of APP by $\beta$ - and $\gamma$-secretases results in production of amyloid $\beta$ (A $\beta$ ) peptides. The major $A \beta$ species are 40 and 42 amino acid long peptides, the latter of which is recognized as the more toxic species involved in Alzheimer's disease (AD) pathogenesis [2,6,7]. Factors that modulate the $A \beta_{42 / 40}$ ratio can be classified into at least two categories; 1 ) substrate-targeting manipulations, such as FAD-linked mutations within the intramembranous region of the APP substrate [8,9], and 2) $\gamma$-secretase-targeting modifications, such as FAD-linked PS1 mutations [10-12], Pen-2 N-terminus modification [13] or expression of different Aph1 isoform [14]. In addition, treatment with pharmacological agents, $\gamma$ secretase modulators (GSMs), could alter the $A \beta_{42 / 40}$ ratio [15-17]. However, there is a controversy whether

\footnotetext{
* Correspondence: oberezovska@partners.org

${ }^{1}$ Alzheimer Research Unit, MassGeneral Institute for Neurodegenerative Diseases, Massachusetts General Hospital, Charlestown, MA 02129, USA Full list of author information is available at the end of the article
}

the primary target of these compounds is APP substrate [18-20], or PS1/ $\gamma$-secretase [21-25].

Using Förster resonance energy transfer (FRET)/fluorescent lifetime imaging microscopy (FLIM) technique, we have previously demonstrated that PS1, a catalytic site of $\gamma$-secretase, could exist in a "closed" (close proximity between the PS1 N-terminus, C-terminus, and a large cytoplasmic loop domain) and "open" (longer distance between them) conformations [26-28]. Although the detailed molecular mechanism responsible for different PS1 conformational states, and underlying the precision of APP cleavage by PS $1 / \gamma$-secretase is currently unknown, we found that the "closed" conformation of PS1 is consistently linked to a higher $A \beta_{42 / 40}$ ratio, whereas the "open" conformation is associated with a lower $\mathrm{A} \beta_{42 / 40}$ ratio [26-28].

Notably, in addition to manipulations directly targeting components of the $\gamma$-secretase complex, mutations within the transmembrane region of the APP substrate have been shown to induce changes in the PS1 conformation. For example, APP with FAD-linked V717I or I716F mutations that increase the $A \beta_{42 / 40}$ ratio seem to associate with the PS1/ $\gamma$-secretase earlier in the secretory pathway, alter the alignment of APP with PS1, and shift PS1 into a "close" NT and CT proximity conformation [29].
C Biomed Central

(C) 2011 Uemura et al; licensee BioMed Central Ltd. This is an Open Access article distributed under the terms of the Creative Commons Attribution License (http://creativecommons.org/licenses/by/2.0), which permits unrestricted use, distribution, and reproduction in any medium, provided the original work is properly cited. 
Conversely, the APP V715F substitution, which dramatically decreases the $A \beta_{40}$ and $A \beta_{42}$ while increasing $A \beta_{38}$ levels, induced a structural rearrangements in PS1 reminiscent of that observed after the treatment with $A \beta_{42}$ -lowering non-steroidal anti-inflammatory drugs ("open" conformation) [30].

Based on these findings, we hypothesized that APPtargeting manipulations may alter conformation of the APP molecule or it's positioning within the plane of the membrane. This alteration may change APP substrate presentation to the $\mathrm{PS} 1 / \gamma$-secretase, and consequently induce a shift in PS1 conformation. Since previous structural analysis predicts that the APP cytoplasmic domain can associate with the membrane and alter its positioning in response to various stimuli [31], in the current study we analyzed proximity between the membrane and APP-CT as readout of APP transmembrane positioning. Thus, to better understand the relationship between APP CT transmembrane positioning, PS $1 / \gamma$ secretase conformation, and the $A \beta_{42 / 40}$ ratio, we asked whether APP-CT proximity to the membrane correlates with the $A \beta_{42 / 40}$ ratio and can be affected by the PS1 conformational change. The FLIM assay was utilized to monitor relative distance between the two fluorophores labelling membrane and APP-CT in intact cells. We found that FAD mutations within the APP transmembrane domain, that raise the $A \beta_{42 / 40}$ ratio, increase proximity of the APP-CT to the membrane. Interestingly, treatment of cells with GSMs, which are known to modify the $A \beta_{42 / 40}$ ratio and induce PS1 conformational change $[24,26,28]$, led to altered APP-CT and membrane proximity only in the presence of $\mathrm{PS} 1 / \gamma$-secretase. Surprisingly, we found that $A \beta_{42 / 40}$ ratio-raising FAD-linked mutations in PS1 also affect the positioning of APP relative to the membrane in a manner similar to that of the FAD-linked APP mutations. These results suggest a reciprocal relationship between conformation of the APP-CT and/or its orientation relative to the membrane and PS1 conformation. Thus, factors that modulate either APP positioning or PS1 conformation could be exploited therapeutically to correct pathogenic $A \beta_{42 / 40}$ ratio, and thus prevent or slow down progression of $\mathrm{AD}$.

\section{Results}

The $A \boldsymbol{\beta}_{42 / 40}$ ratio-raising APP mutations increase the proximity between APP-CT and the membrane

First, we measured the effect of V717I, V717K or I716F mutations located in the transmembrane domain of APP on the $A \beta_{42 / 40}$ ratio in $\mathrm{CHO}$ cells transiently transfected with the mutant APP constructs. As reported previously $[8,9]$, the amount of $A \beta_{42}$ was increased while the amount of the $A \beta_{40}$ was decreased in the conditioned medium of V717I and I716F APP expressing cells, leading to a significantly elevated $A \beta_{42 / 40}$ ratio
(Figure 1A). By contrast, artificial V717K APP mutation [32] significantly lowered the $A \beta_{42 / 40}$ ratio.

To determine whether these APP mutations affect APP-CT proximity to the membrane, APP-CT-RFP (wild-type or mutant) was co-transfected with either myrGFP or EGFP into APP/APLP2 dKO cells, and the lifetime of GFP donor was measured by FLIM. MyrGFP has a myristoylation sequence that restricts expression of GFP to the membrane [33]. In cells transfected with the myrGFP and wild-type APP-RFP, the lifetime of donor GFP was shortened, compared to that in the myrGFP only expressing cells. This indicates energy transfer from myrGFP to RFP, and close proximity between the APP-CT and membrane. However, in cells transfected with the EGFP without myristoylation signal, the donor lifetime did not change significantly by coexpression with the APP-RFP (Figure 1B, C), confirming specificity of the FRET signal in the former, and close proximity of the APP CT to the membrane.

Interestingly, cells transfected with APP-RFP mutants that yield high $A \beta_{42 / 40}$ ratio (V717I and I716F) showed shorter myrGFP donor lifetime, compared to that in cells transfected with the wild-type APP-RFP (Figure $1 C$ ), indicating increased proximity between mutant APP-CT and the membrane. As expected, APP-RFP V717I mutant did not shorten the lifetime of EGFP without myristoylation signal, confirming that the observed shortening of the myrGFP lifetime was specifically caused by the closer proximity of the RFP acceptor at V717I and I716F APP C-termini to the membrane. Conversely, myrGFP donor lifetime was significantly longer in cells expressing $A \beta_{42 / 40}$ ratio-lowering V717K APP-RFP mutant, compared to that in the wild-type APP-RFP cells (Figure 1C). The level of expression for different APP mutants is shown in Additional file 1, Figure S1. Please note, APP I716F and V717K mutants are expressed at comparable levels, however, these mutations affect APP-RFP proximity to the membrane in an opposite fashion, as detected by the FLIM assay. Moreover, additional tests were performed to demonstrate that the levels of APP-RFP (Additional file 1, Figure S2) or PS1 (Additional file 1, Figure S3) expression do not affect the myrGFP donor fluorophore lifetime in the FLIM assay. This further confirms that it is the $A \beta_{42 / 40}$ ratio altering mutations, and not the level of expression, that affect APP CT proximity relative to the membrane.

We used a two-exponential model of the lifetime analysis for the measurement of myrGFP and APP-CT proximity (see Methods and [24,27]). First, the baseline myrGFP lifetime ( $t 1$, no FRET) is established in the absence of an acceptor fluorophore. When myrGFP (membrane) and APP-RFP proximity is analysed, the population with a longer lifetime (no FRET) is "fixed", i.e. excluded from the lifetime analysis, and a shorter 


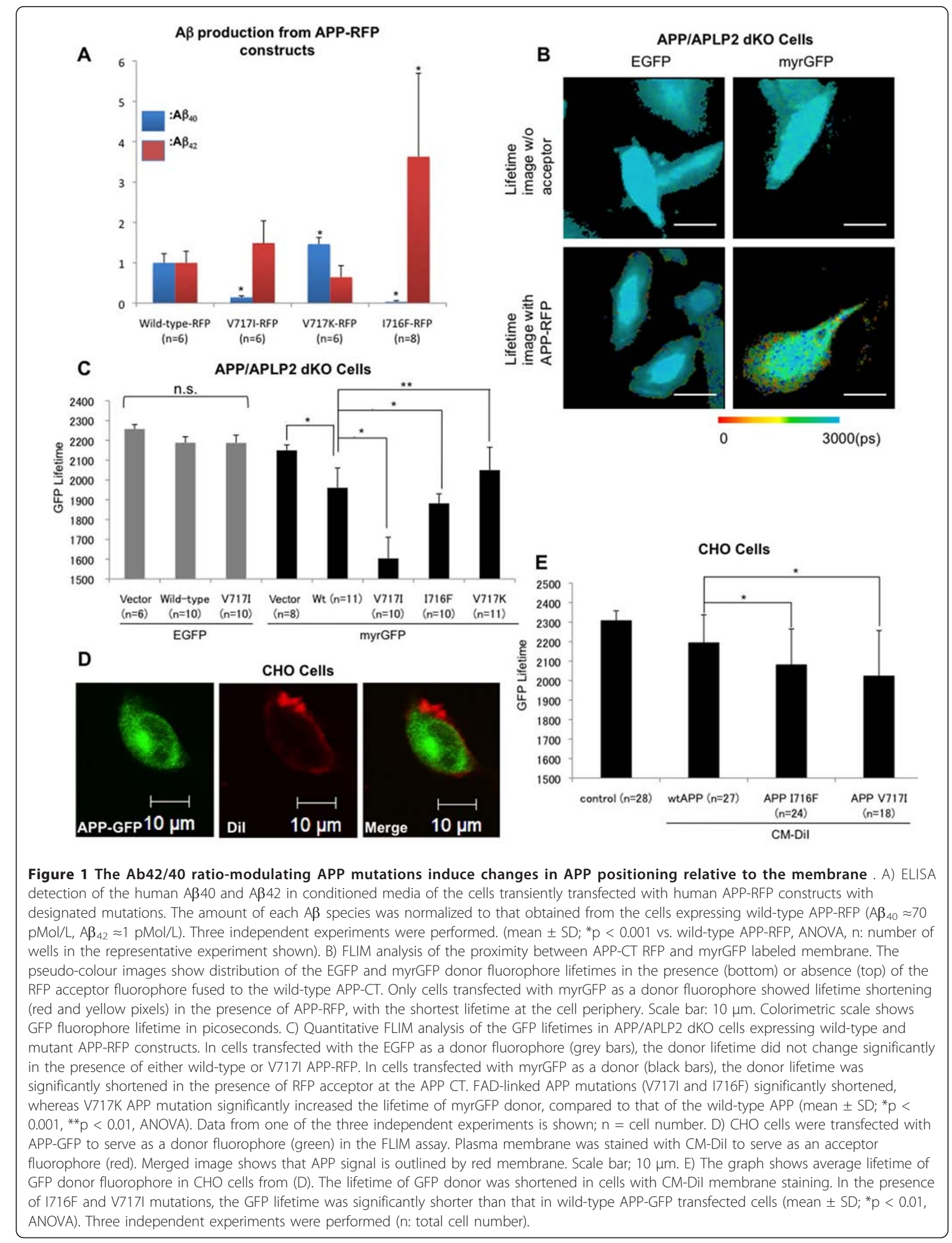


lifetime of a second, FRET-ing population (t2) is recorded. Thus, parts of the myrGFP labelled membrane that do not contain RFP-labeled APP (or most of the APP molecules not interacting with PS $1 / \gamma$-secretase, see bellow) have been excluded from the analysis and comparisons between different experimental conditions.

To verify the above finding, we used an alternative strategy by reversing the donor and acceptor fluorophores. GFP fused to the APP-CT served as a donor fluorophore, and CM-DiI was used to stain the membrane, and served as a FRET acceptor (Figure 1D). As expected, in the presence of CM-DiI staining, the lifetime of GFP was significantly shortened, indicating energy transfer from the GFP to DiI, and close proximity of the APP-CT to the membrane (Figure 1E). Presence of the $A \beta_{42}$-raising APP mutations led to a further shortening of the APP-GFP lifetime (Figure 1E), confirming that APP mutations caused a shift in the APP-CT orientation relative to the membrane.

\section{$\gamma$-Secretase modulators (GSMs) cause a shift in the APP positioning within the membrane}

It has been reported recently $[18,19]$ that $A \beta_{42 / 40}$ ratiomodulating GSMs could directly bind to the APP substrate. Thus, we tested whether GSMs affect the $A \beta_{42 / 40}$ ratio by altering APP membrane positioning. For this, APP/APLP2 dKO cells co-transfected with myrGFP and wild-type APP-RFP were treated with either $A \beta_{42}$-raising (fenofibrate, celecoxib) or $A \beta_{42}$-lowering (ibuprofen, indomethacin, flurbiprofen) GSMs. We found that fenofibrate and celecoxib treatment significantly decreased the lifetime of myrGFP donor, compared to the vehicle control treatment, indicating that they changed positioning of the APP-CT relative to the membrane in the same direction as $A \beta_{42 / 40}$ ratio-raising APP FAD mutations (Figure 2A). Conversely, treatment with $\mathrm{A} \beta_{42^{-}}$ lowering GSMs increased the donor lifetime (Figure 2A). These findings support the idea that change in the positioning of APP-CT to the membrane reflects a change in the $A \beta_{42 / 40}$ ratio, with shorter distance between the APP$\mathrm{CT}$ and membrane correlating with a higher, and longer distance with a lower $A \beta_{42 / 40}$ ratio.

Our previous studies showed that fenofibrate and ibuprofen could also allosterically modify PS1 conformation. To demonstrate whether there is any interplay between the APP-CT position and PS1 conformation, we asked whether GSMs could affect APP-CT orientation in the absence of PS $1 / \gamma$-secretase. To answer this question, PS1/2 dKO cells co-transfected with myrGFP and wild-type APP-RFP were treated with either ibuprofen or fenofibrate. We found that treatment with neither one of the GSMs affect the lifetime of myrGFP donor in the absence of PS1/2 (Figure 2B). Moreover, our data indicate that APP-CT locates far from the membrane so that the distance cannot support the energy transfer from myrGFP to RFP on the APP-CT in the absence of presenilins.

To establish whether PS1 $/ \gamma$-secretase presence and/or interaction with the APP substrate are needed to change positioning of APP-CT relative to the membrane, we used the previously characterized helical peptide (HP) $\gamma$-secretase inhibitor, which docks to the substrate-binding site on $\gamma$-secretase and prevents binding of APP to the PS1 $/ \gamma$-secretase [34]. Wild-type APP-RFP was transfected into either PS1/2 dKO cells or PS1/2 dKO cells reconstituted by stable expression of the wild-type PS1 (PS1/2 dKO + wild-type PS1 cells). Once again, the expression of APP-RFP did not alter the lifetime of donor myrGFP in PS1/2 dKO cells, indicating that APP$\mathrm{CT}$ and the membrane are not close enough to support FRET in the absence of presenilins. On the contrary, the donor lifetime was significantly shortened in PS1/2 dKO + wild-type PS1 cells, indicating that APP-CT proximity to the membrane changes in the presence of PS1. When APP docking to PS1 $/ \gamma$-secretase was inhibited by HP treatment in PS1/2 dKO + wild-type PS1 cells, we observed a significant increase in the myrGFP donor lifetime, confirming that APP-PS1 interaction affects the positioning of APP-CT (Figure 2C). As mentioned above, the twoexponential FLIM analysis of APP-PS1 interactions, which monitors only those APP molecules that do interact with PS1 $\gamma$-secretase, leads to increased sensitivity of the assay to "presenilin effects" on APP-CT orientation towards the membrane.

Similar results were obtained after HP treatment of the APP/APLP2 dKO cells transfected with APP-RFP and expressing wild-type PS1 on endogenous levels (Additional file 1, Figure S4), indicating that APP binding/interaction with the $\mathrm{PS} 1 / \gamma$-secretase rearranges the APP-CT positioning.

\section{FAD-linked PS1 mutations alter APP-CT positioning relative to the membrane}

We have previously found that FAD-linked PS1 mutants modify PS1 conformation, and as a result alter an alignment of PS1/ $\gamma$-secretase with the APP substrate [27]. To test whether this may lead to a change in the positioning of APP-CT relative to the membrane, we monitored proximity between the membrane and APP-CT in PS1/2 $\mathrm{dKO}$ cell lines, reconstituted by stable expression of either wild-type PS1 or PS1 with FAD-linked mutations (L166P, Delta9, A246E). Indeed, we found that expression of each FAD-linked PS1 mutation caused a change in the APP-CT positioning (shortening of the GFP donor lifetime) (Figure 3A), similar to that caused by the FAD APP mutations.

To confirm this finding, PS1/2 dKO cells were transiently co-transfected with either wild-type PS1, FAD-linked 

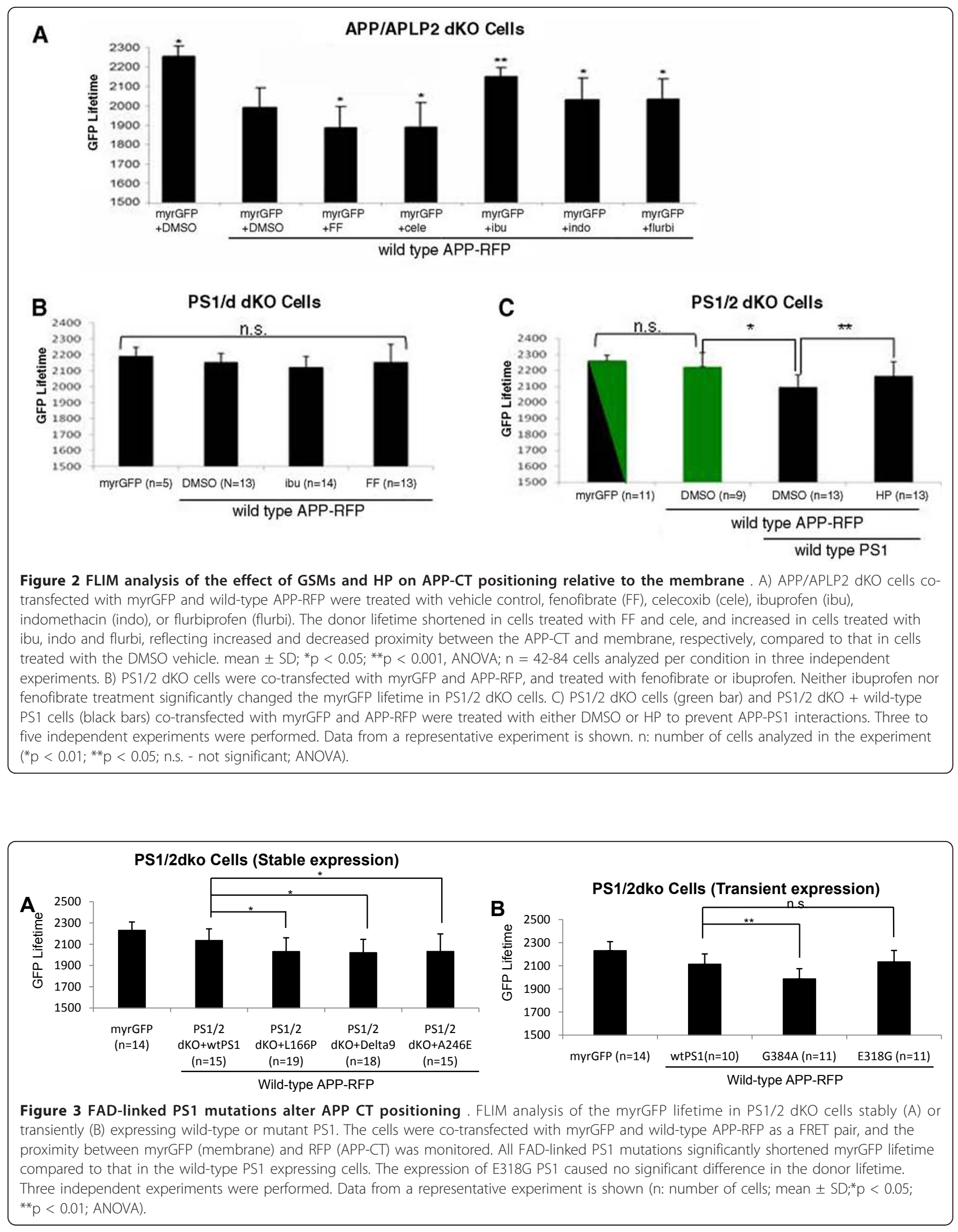
G384A PS1, or non-pathogenic E318G PS1 polymorphism together with the myrGFP and wild-type APP-RFP. As expected, expression of the G384A mutant PS1 shortened the lifetime of myrGFP, compared to that of the wild-type PS1. On the other hand, expression of the E318G PS1 polymorphism had no effect on the myrGFP lifetime (Figure 3B), indicating that FAD-linked mutations, but not a benign polymorphism, alter APP-CT orientation relative to the membrane. Thus, these findings demonstrate that altered conformation of the FAD mutant PS1 and resulting "misalignment" with the APP substrate that leads to increased $A \beta_{42 / 40}$ ratio, also changes positioning of the APP-CT.

\section{Discussion}

The cytoplasmic domain of APP is believed to function in multiple signalling pathways ranging from apoptosis to gene transcription regulation [35]. APP intracellular domain has been shown to interact with various molecules and contribute to axonal transport [36], neurite outgrowth and arborization [37], and signalling events in the cell $[38,39]$. Thus, alterations in APP-CT structure in pathological settings could ultimately interfere with these events and accelerate neuropathological changes. A potential relationship between the APP-CT conformation and $\mathrm{A} \beta$ production has been suggested. For example, structural studies of the APP-CT have demonstrated that although APP-CT does not adopt a stable folded conformation, it has a transient preordered structure, whose conformation can be altered by phosphorylation $[40,41]$. In addition, a recent structural model predicts that APP-CT might be associated with the membrane, and suggests that APP-CT association with and dissociation from the membrane might regulate interactions of APP with various proteins [31], and could contribute to an altered $A \beta_{42 / 40}$ ratio. A new $\gamma$-secretase activating protein has been recently described that interacts with both PS1 and APP C-terminal fragment (but not with the Notch substrate), affects $\mathrm{A} \beta$ production, and may alter the structural relationship between $\gamma$-secretase and APP CT [42].

A model in which there is successive release of tripeptides has been proposed for differential production of the $A \beta_{40}$ and $A \beta_{42}$ species $[43,44]$. According to this model, $\mathrm{A} \beta_{49}$ produced by $\mathrm{PS} 1 / \gamma$-secretase dependent $\varepsilon$-cleavage of APP at the membrane-cytosol interface is converted to $A \beta_{40}$ after successive release of tri-peptides, whereas initial $\varepsilon$-cleavage of APP at the $A \beta_{48}$ site is converted to the $A \beta_{42}$. In the present study, we employed the FLIM assay in intact cells to demonstrate that APP$\mathrm{CT}$ positioning relative to the membrane, or a conformational change of the APP/C99 cytoplasmic domain, correlates with changes in the $A \beta_{42 / 40}$ ratio. We found that $A \beta_{42 / 40}$ ratio-raising mutations in PS1 or in the
APP transmembrane region altered APP positioning within the membrane by bringing the APP C-terminus closer to the membrane. Thus, a conformational change of the APP cytoplasmic domain, which we observed in the current study, may affect the initial APP cleavage at the $\varepsilon$-site by altering APP substrate presentation to PS1/ $\gamma$-secretase at the membrane-cytosol interface.

Interestingly, we found that PS $1 / \gamma$-secretase itself has a profound effect on APP-CT positioning relative to the membrane. First, our data indicate that in the absence of PS $1 / \gamma$-secretase or when APP-PS1 $/ \gamma$-secretase interaction is inhibited by HP treatment, FRET between APP-CT-RFP and myrGFP-membrane is absent, suggesting that the distal part of the APP-CT is located relatively far away from the membrane. Surprisingly, it appears as if interaction of APP with the PS $1 / \gamma$-secretase affects the orientation of APP-CT by bringing it into close proximity to the membrane (FRET present). Moreover, interactions with FAD mutant PS $1 / \gamma$-secretase further change the positioning of the APP-CT to obtain an even closer proximity relative to the membrane. Although the precise mechanism of how mutations in PS1 affect APP positioning relative to the membrane is unknown, it is possible that in the process of APP substrate alignment with the topographically altered mutant $\gamma$-secretase active site, changes in the APP-CT membrane proximity occur. This is in agreement with a cross-linking experiment demonstrating that aggressive FAD-linked PS1 mutations cause alterations in topography of the $\gamma$-secretase active site [45].

GSMs have been shown to affect both PS1 conformation [13,24,26-28], as well as APP positioning in the membrane (current study). There remains an uncertainty over the primary target of GSMs, with some studies showing that GSMs target $\gamma$-secretase, either PS1 itself or other components, such as Pen2, [21,22,42], whereas others propose that GSMs directly bind to the APP substrate [18-20]. In our current study, we did not observe any effect of GSMs on APP-CT positioning in the absence of PS1 and PS2. However, we could not exclude the possibility that GSMs binding may have a subtle effect within the range of nonFRETing distance $(>10 \mathrm{~nm})$ from the membrane in PS1/2 $\mathrm{dKO}$ cells, thus rendering the APP-CT positioning change undetectable by our current method. It is also possible that some GSMs could still bind to APP CTF in the absence of presenilins but it requires the complex formation for the conformational shift to occur. We have recently reported that the modulatory effect of GSMs is implemented through the "allosteric site" located within the $\gamma$-secretase complex itself, although substrate docking to $\gamma$-secretase is needed to allow GSM access to this site [24]. Thus, the most likely scenario is that these GSMs primarily target PS $1 / \gamma$-secretase or the PS1/APP interface, and the change in APP positioning within the membrane is a secondary response to the change of PS1 conformation. 


\section{Conclusions}

In summary, our data demonstrate that interaction of the APP substrate with PS1/ $\gamma$-secretase changes APP CT positioning relative to the membrane. Moreover, both APP-targeting and PS1-targeting manipulations that change the $A \beta_{42 / 40}$ ratio can affect APP orientation relative to the membrane as well as PS1 conformation, indicating that APP-CT positioning and PS1 conformation are tightly interconnected, and are in a reciprocal relationship (Figure 4). Thus, exploring factors affecting PS1 as well as APP conformation would render more insights into the AD pathogenesis, and may provide new information about potential therapeutic targets.

\section{Methods}

Cell Lines and Pharmacological treatments

PS1/PS2 double knockout (PS1/2 dKO) mouse embryonic fibroblasts (MEFs), and PS1/2 dKO cells reconstituted by stable expression of wild-type or FAD-linked PS1 (L166P, Delta9 and A246E) were a generous gift from Dr. Bart Destrooper [46]. APP/APLP2 dko MEFs were generous a gift from Dr. Koo. Chinese Hamster Ovary $(\mathrm{CHO})$ cells were obtained from ATCC. Cells were cultured with Opti-MEM (Invitrogen) supplemented with $5 \%$ fetal bovine serum. The cells plated into four-chamber slides were transfected with various constructs, and were subjected to microscopy (FRET, FLIM) analyses. To evaluate the effect of GSMs on APP, the cells were treated for 24 hours with either $100 \mu \mathrm{M}$ fenofibrate or $400 \mu \mathrm{M}$ ibuprofen. To inhibit the interaction between APP and PS1 $\gamma$-secretase, cells were treated for 24 hours with $100 \mathrm{nM}$ helical peptide (a gift from Dr. M. Wolfe, BWH, Boston, MA), which was designed to mimic a portion of the APP transmembrane domain and competes with APP for binding to PS $1 / \gamma$-secretase [34]. Control cells were treated with a vehicle (either DMSO or ethanol).

\section{Constructs}

Human APP 695 isoform was tagged with either green or red fluorescent protein at its $\mathrm{C}$-terminus to generate APP-GFP and APP-mRFP constructs, respectively. APP mutations (V717I, V717K, I716F) were inserted using Quick Change Site-Directed mutagenesis kit (Stratagene), according to the manufacturer's instructions. GFP with myristoylation signal at the $\mathrm{N}$-terminus was
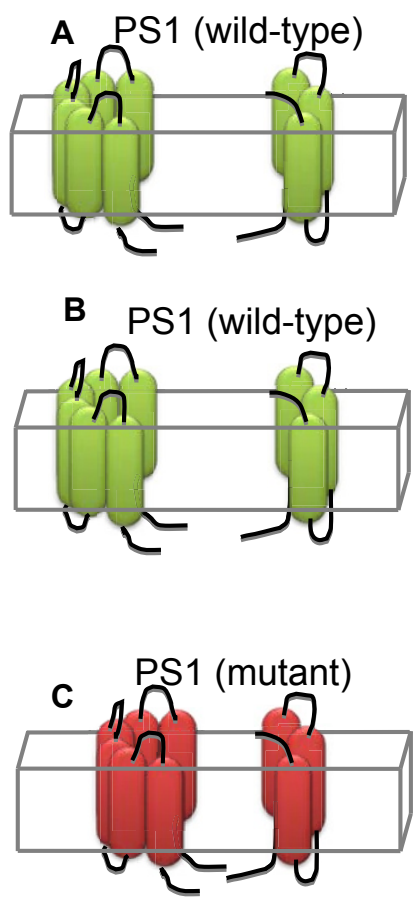
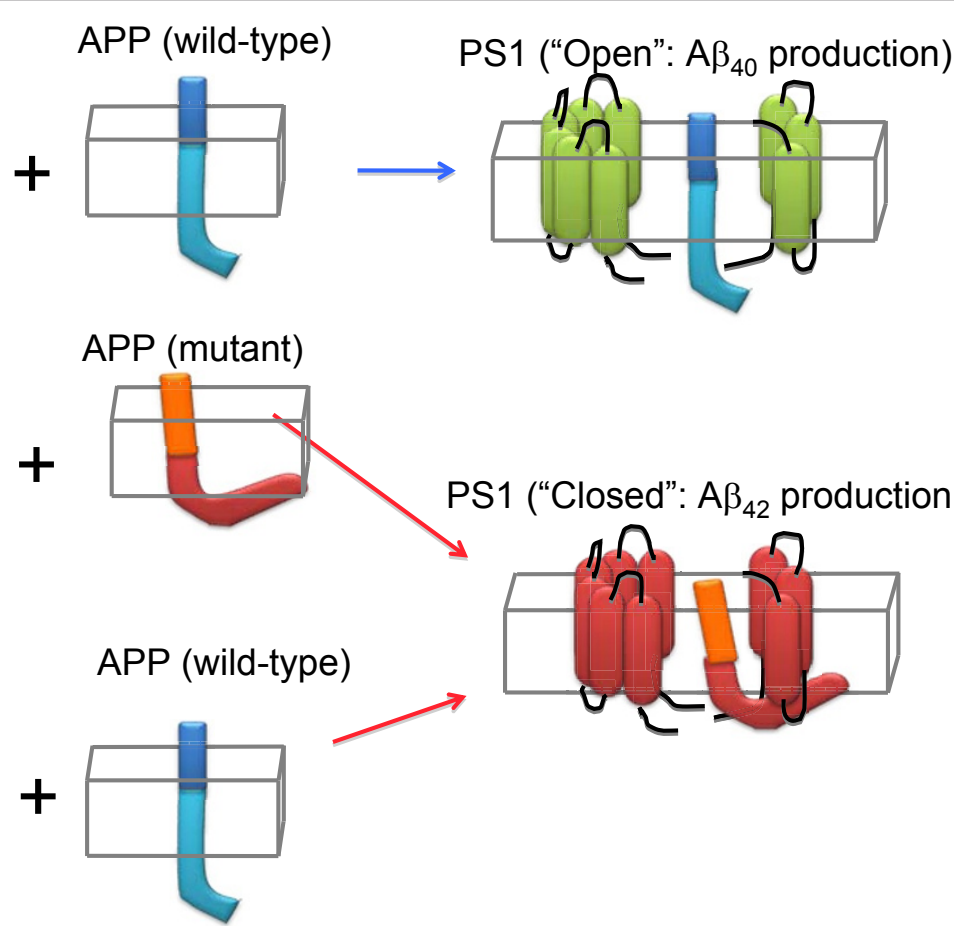

PS1 ("Closed": $A \beta_{42}$ production)

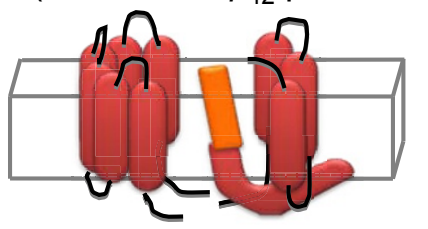

Figure $4 \mathrm{~A}$ scheme of reciprocal interaction between APP-CT positioning relative to the membrane and PS1 conformation . Wild type PS1/ $\gamma$-secretase can exist in an "open" and "close" conformational states that correlate with production of A 40 and A 42 , respectively (Lleo, 2004, Berezovska 2005), with the "open" conformation being a predominant state (A). The C-terminus of APP bearing FAD mutation(s) associated with the increased $A \beta_{42 / 40}$ ratio (orange/red) positions closer to the membrane (B), compared to that in the wild type APP (A). When incorporated into wild type PS1/ $\gamma$-secretase, it can induce conformational change of PS1 by bringing PS1 NT and CT closer together [25]. On the other hand, when wild type APP is incorporated into FAD-mutant PS1/ $\gamma$-secretase that predominantly exist in a "closed" conformation, the position of APP C-terminus changes and comes closer to the membrane (C). 
described previously [33]. EGFP-C3 empty vector (Clontech, Madison, WI) was used as a control for expression of EGFP without a membrane targeting signal. Wildtype PS1, as well as E318G and G384A mutant PS1 constructs were described previously [27].

\section{Fluorescence Lifetime Imaging Microscopy (FLIM)}

FLIM was used as an approach to monitor proximity between the myrGFP labeled membrane and APP-CTRFP. Briefly, cells expressing myrGFP only were used as a negative control to determine the baseline myrGFP lifetime. The degree of GFP donor lifetime shortening due to presence of FRET was used as an indicator of the proximity between the GFP donor and RFP acceptor fluorophores in myrGFP and APP-RFP cotransfected cells. The FLIM software uses the Levenberg-Marquardt algorithm to fit the raw data from each pixel to two-exponential fluorescence decay curves to record presence of a shorter than baseline GFP lifetime (for details please see [24,27].

Alternatively, the plasma membrane was labelled with CM-DiI (Molecular Probes) as an acceptor fluorophore in the FLIM assay, and GFP-donor was fused to the APP CT. In this case, cells expressing APP-CT-GFP but not labelled with the CM-DiI served as a negative control. To label the membrane, cells were incubated with $1 \mu \mathrm{g} / \mathrm{ml}$ of CM-DiI dissolved in PBS for 15 minutes at $4^{\circ} \mathrm{C}$ and fixed with $4 \%$ paraformaldehyde, prior to the FLIM analysis. Data analysis was performed using SPC Image (Becker\&Hickl, Berlin, Germany), in which donor fluorophore lifetimes are determined by fitting the data to one (negative control) or two (experimental conditions) exponential decay curves. In two component analysis, GFP lifetime (negative control with no acceptor fluorophore) is monitored first, and its value is "fixed" as $\mathrm{t} 1$ lifetime. The second, shorter lifetime representing FRET is calculated by the system as $\mathrm{t} 2$ value. This $\mathrm{t} 2$ value was used for comparisons between different experimental conditions. Thus, "non-FRETing" component ( $\mathrm{t} 1$ lifetime representing APP molecules that do not interact with PS1, and thus position in the membrane in such a way that does not support FRET) is excluded from the lifetime comparisons.

\section{ELISA}

To measure the effect of APP mutations on $A \beta$ production, wild-type APP-RFP, or APP-RFP, with V717I, V717K or I716F mutations were transfected into $\mathrm{CHO}$ cells cultured in $35 \mathrm{~mm}$ dishes. 6 hours after the transfection, culture medium was exchanged with $1 \mathrm{ml}$ of fresh OPTI-MEM with $1 \%$ FBS, and cells were grown for an additional 24 hours. The conditioned medium was subjected to ELISA analysis using human $\beta$-amyloid (1-40 and 1-42) ELISA kit (WAKO, JAPAN), according to the manufacturer's instruction.

\section{Statistical analysis}

StatView for Windows, Version 5.0.1 (SAS Institute, Inc) was employed to perform statistical analysis using Fisher's PSLD analysis of variance (ANOVA). Samples were considered significantly different at $\mathrm{p}<0.05$.

\section{Additional material}

\begin{abstract}
Additional file 1: Inhibition of APP-PS1/g-secretase interaction, and not the level of expression, alters APP-CT positioning to the membrane. (Figure S1)- Level of expression of the wild type (wt), and V717I, I716F and V717K APP mutants in APP/APLP2 dko cells. Level of expression of the wild type APP-RFP (Figure S2) or PS1 (Figure S3) does not alter APP C-terminus positioning relative to membrane, as detected by the FLIM assay (graph in B and C). (Figure S4)- FLIM analysis of APP/ APLP2 dKO cells co-transfected with myrGFP and wild-type APP-RFP, and treated with either DMSO or docking site $\gamma$-secretase inhibitor, HP. The lifetime of donor myrGFP was significantly longer in cells treated with the HP, compared to that in cells treated with the DMSO (mean $\pm \mathrm{SD}$; * $p<0.05$, ANOVA). Results from three independent experiments are shown. (n: number of cells examined.)
\end{abstract}

\section{Acknowledgements}

We are grateful to Dr. Bradley T. Hyman for helpful discussions, to Ms. Mary Banks for technical assistance, to Drs. Koo (UCSD) and DeStrooper (VIB, Belgium) for PS1/2 dko and APP/APLP2 dko MEF cells, respectively; and to Dr. Wolfe (BWH, Boston) for HP. This work was supported by AG026593 and AG15379 (OB)

\section{Author details}

${ }^{1}$ Alzheimer Research Unit, MassGeneral Institute for Neurodegenerative Diseases, Massachusetts General Hospital, Charlestown, MA 02129, USA

${ }^{2}$ Kyoto University, Graduate School of Medicine, Japan.

\section{Authors' contributions}

$\mathrm{KU}$ and PJ carried out the FLIM study. KU analyzed the data and drafted the manuscript. KCF carried out the ELISA, NNG performed western blotting. OB conceived the study, and participated in its design, discussion of the data, and helped to write the manuscript. All authors read and approved the final manuscript.

\section{Competing interests}

The authors declare that they have no competing interests.

Received: 20 August 2010 Accepted: 10 February 2011 Published: 10 February 2011

\section{References}

1. Wolfe MS, Xia W, Ostaszewski BL, Diehl TS, Kimberly WT, Selkoe DJ: Two transmembrane aspartates in presenilin-1 required for presenilin endoproteolysis and gamma-secretase activity. Nature 1999, 398:513-7.

2. Hardy J, Selkoe DJ: The amyloid hypothesis of Alzheimer's disease: progress and problems on the road to therapeutics. Science 2002, 297:353-6, (2002).

3. Sisodia SS, St George-Hyslop PH: gamma-Secretase, Notch, Abeta and Alzheimer's disease: where do the presenilins fit in? Nat Rev Neurosci 2002, 3:281-90

4. Selkoe DJ, Kopan R: Notch and Presenilin: regulated intramembrane proteolysis links development and degeneration. Annu Rev Neurosci 2003, 26:565-97.

5. De Strooper B: Aph-1, Pen-2, and Nicastrin with Presenilin generate an active gamma-Secretase complex. Neuron 38:9-12.

6. Jarrett JT, Berger EP, Lansbury PT Jr: The carboxy terminus of the beta amyloid protein is critical for the seeding of amyloid formation: implications for the pathogenesis of Alzheimer's disease. Biochemistry 1993, 32:4693-7. 
7. Iwatsubo T, Odaka A, Suzuki N, Mizusawa H, Nukina N, Ihara Y: Visualization of $A$ beta $42(43)$ and $A$ beta 40 in senile plaques with end-specific $A$ beta monoclonals: evidence that an initially deposited species is $\mathrm{A}$ beta 42(43). Neuron 1994, 13:45-53.

8. Goate A, Chartier-Harlin MC, Mullan M, Brown J, Crawford F, Fidani L, Giuffra L, Haynes A, Irving N, James L, et al: Segregation of a missense mutation in the amyloid precursor protein gene with familial Alzheimer's disease. Nature 1991, 349:704-6.

9. Guardia-Laguarta C, Pera M, Clarimón J, Molinuevo JL, Sánchez-Valle R, Lladó A, Coma M, Gómez-Isla T, Blesa R, Ferrer I, Lleó A: Clinical, neuropathologic, and biochemical profile of the amyloid precursor protein I716F mutation. J Neuropathol Exp Neurol 2010, 69:53-9.

10. Sherrington R, Rogaev El, Liang Y, Rogaeva EA, Levesque G, Ikeda M, Chi H, Lin $C, L i$ G, Holman $K$, et al: Cloning of a gene bearing missense mutations in early-onset familial Alzheimer's disease. Nature 1995, 375:754-60.

11. Cruts M, Backhovens H, Wang SY, Van Gassen G, Theuns J, De Jonghe CD, Wehnert A, De Voecht J, De Winter G, Cras P, et al: Molecular genetic analysis of familial early-onset Alzheimer's disease linked to chromosome 14q24.3. Hum Mol Genet 1995, 4:2363-71.

12. Perez-Tur J, Froelich S, Prihar G, Crook R, Baker M, Duff K, Wragg M, Busfield F, Lendon C, Clark RF, et al: A mutation in Alzheimer's disease destroying a splice acceptor site in the presenilin-1 gene. Neuroreport 1995, 7:297-301.

13. Isoo N, Sato C, Miyashita H, Shinohara M, Takasugi N, Morohashi Y, Tsuji S, Tomita T, Iwatsubo T: Abeta42 overproduction associated with structural changes in the catalytic pore of gamma-secretase: common effects of Pen-2 N-terminal elongation and fenofibrate. J Biol Chem 2007, 282:12388-96.

14. Serneels L, Van Biervliet J, Craessaerts K, Dejaegere T, Horré K, Van Houtvin T, Esselmann H, Paul S, Schäfer MK, Berezovska O, Hyman BT, Sprangers B, Sciot R, Moons L, Jucker M, Yang Z, May PC, Karran E, Wiltfang J, D'Hooge R, De Strooper B: gamma-Secretase heterogeneity in the Aph1 subunit: relevance for Alzheimer's disease. Science 2009, 324:639-42.

15. Weggen S, Eriksen JL, Das P, Sagi SA, Wang R, Pietrzik CU, Findlay KA, Smith TE, Murphy MP, Bulter T, Kang DE, Marquez-Sterling N, Golde TE, Koo EH: A subset of NSAIDs lower amyloidogenic Abeta42 independently of cyclooxygenase activity. Nature 2001, 414:212-6.

16. Eriksen JL, Sagi SA, Smith TE, Weggen S, Das P, McLendon DC, Ozols W, Jessing KW, Zavitz KH, Koo EH, Golde TE: NSAIDs and enantiomers of flurbiprofen target gamma-secretase and lower Abeta 42 in vivo. J Clin Invest 2003, 112:440-9.

17. Kukar T, Murphy MP, Eriksen JL, Sagi SA, Weggen S, Smith TE, Ladd T, Khan MA, Kache R, Beard J, Dodson M, Merit S, Ozols W, Anastasiadis PZ, Das P, Fauq A, Koo EH, Golde TE: Diverse compounds mimic Alzheimer disease-causing mutations by augmenting Abeta42 production. Nat Med 2005, 11:545-50

18. Kukar TL, Ladd TB, Bann MA, Fraering PC, Narlawar R, Maharvi GM, Healy B, Chapman R, Welzel AT, Price RW, Moore B, Rangachari V, Cusack B, Eriksen J, Jansen-West K, Verbeeck C, Yager D, Eckman C, Ye W, Sagi S, Cottrell BA, Torpey J, Rosenberry TL, Fauq A, Wolfe MS, Schmidt B, Walsh DM, Koo EH, Golde TE: Substrate-targeting gamma-secretase modulators. Nature 2008, 453:925-9.

19. Richter L, Munter LM, Ness J, Hildebrand PW, Dasari M, Unterreitmeier S, Bulic B, Beyermann M, Gust R, Reif B, Weggen S, Langosch D, Multhaup G: Amyloid beta 42 peptide (Abeta42)-lowering compounds directly bind to Abeta and interfere with amyloid precursor protein (APP) transmembrane dimerization. Proc Natl Acad Sci USA 2010, 107:14597-602.

20. Botev A, Münter LM, Wenzel R, Richter L, Althoff V, Ismer J, Gerling U, Weise C, Koksch B, Hildebrand PW, Bittl R, Multhaup G: The APP C-terminal fragment $\mathrm{C} 100$ occurs in monomeric and dimeric stable conformations and binds gamma-secretase modulators. Biochemistry 2010, 50(5):828-35.

21. Weggen S, Eriksen JL, Sagi SA, Pietrzik CU, Ozols V, Fauq A, Golde TE, Koo EH: Evidence that nonsteroidal anti-inflammatory drugs decrease amyloid beta 42 production by direct modulation of gamma-secretase activity. J Biol Chem 2003, 278:31831-7, Epub 2003.

22. Beher D, Clarke EE, Wrigley JD, Martin AC, Nadin A, Churcher I, Shearman MS: Selected non-steroidal anti-inflammatory drugs and their derivatives target gamma-secretase at a novel site. Evidence for an allosteric mechanism. J Biol Chem 2004, 279:43419-26.
23. Shelton CC, Zhu L, Chau D, Yang L, Wang R, Djaballah H, Zheng H, Li YM: Modulation of gamma-secretase specificity using small molecule allosteric inhibitors. Proc Natl Acad Sci USA 2009, 106:20228-33.

24. Uemura K, Farner KC, Hashimoto T, Nasser-Ghodsi N, Wolfe MS, Koo EH, Hyman BT, Berezovska O: Substrate docking to $\gamma$-secretase allows access of $\gamma$-secretase modulators to an allosteric site. Nat Commun 2010, 8:130.

25. Kounnas MZ, Danks AM, Cheng S, Tyree C, Ackerman E, Zhang X, Ahn K, Nguyen P, Comer D, Mao L, Yu C, Pleynet D, Digregorio PJ, Velicelebi G, Stauderman KA, Comer WT, Mobley WC, Li YM, Sisodia SS, Tanzi RE, Wagner SL: Modulation of gamma-secretase reduces beta-amyloid deposition in a transgenic mouse model of Alzheimer's disease. Neuron 2010, 67:769-80.

26. Lleó A, Berezovska O, Herl L, Raju S, Deng A, Bacskai BJ, Frosch MP, Irizarry M, Hyman BT: Nonsteroidal anti-inflammatory drugs lower Abeta42 and change presenilin 1 conformation. Nat Med 2004, 10:1065-6.

27. Berezovska O, Lleo A, Herl LD, Frosch MP, Stern EA, Bacskai BJ, Hyman BT: Familial Alzheimer's disease presenilin 1 mutations cause alterations in the conformation of presenilin and interactions with amyloid precursor protein. J Neurosci 2005, 25:3009-17.

28. Uemura K, Lill CM, Li X, Peters JA, Ivanov A, Fan Z, DeStrooper B, Bacskai BJ, Hyman BT, Berezovska O: Allosteric modulation of PS1/gamma-secretase conformation correlates with amyloid beta(42/40) ratio. PLoS One 2009, 4: e7893.

29. Herl L, Thomas AV, Lill CM, Banks M, Deng A, Jones PB, Spoelgen R, Hyman BT, Berezovska O: Mutations in amyloid precursor protein affect its interactions with presenilin/gamma-secretase. Mol Cell Neurosci 2009, 41:166-74.

30. Tesco G, Ginestroni A, Hiltunen M, Kim M, Dolios G, Hyman BT, Wang R, Berezovska O, Tanzi RE: APP substitutions V715F and L720P alter PS1 conformation and differentially affect Abeta and AICD generation. J Neurochem 2005, 95:446-56.

31. Beel AJ, Mobley CK, Kim HJ, Tian F, Hadziselimovic A, Jap B, Prestegard JH, Sanders CR: Structural studies of the transmembrane C-terminal domain of the amyloid precursor protein (APP): does APP function as a cholesterol sensor? Biochemistry 2008, 47:9428-46.

32. Maruyama K, Tomita T, Shinozaki K, Kume H, Asada H, Saido TC, Ishiura S, Iwatsubo T, Obata K: Familial Alzheimer's disease-linked mutations at Val717 of amyloid precursor protein are specific for the increased secretion of A beta 42(43). Biochem Biophys Res Commun 1996, 227:730-5.

33. Meyer-Luehmann M, Mielke M, Spires-Jones TL, Stoothoff $W$, Jones $P$, Bacskai BJ, Hyman BT: A reporter of local dendritic translocation shows plaque-related loss of neural system function in APP-transgenic mice. $J$ Neurosci 2009, 29:12636-40.

34. Das C, Berezovska O, Diehl TS, Genet C, Buldyrev I, Tsai JY, Hyman BT, Wolfe MS: Designed helical peptides inhibit an intramembrane protease. J Am Chem Soc 2003, 125:11794-5.

35. Reinhard C, Hébert SS, De Strooper B: The amyloid-beta precursor protein: integrating structure with biological function. EMBO J 2005, 24:3996-4006.

36. Kamal A, Almenar-Queralt A, LeBlanc JF, Roberts EA, Goldstein LS: Kinesinmediated axonal transport of a membrane compartment containing beta-secretase and presenilin-1 requires APP. Nature 2001, 414:643-8.

37. Leyssen M, Ayaz D, Hébert SS, Reeve S, De Strooper B, Hassan BA: Amyloid precursor protein promotes post-developmental neurite arborization in the Drosophila brain. EMBO J 2005, 24:2944-55.

38. Cao X, Südhof TC: Dissection of amyloid-beta precursor proteindependent transcriptional transactivation. J Biol Chem 2004, 279:24601-11.

39. Hass MR, Yankner BA: A \{gamma\}-secretase-independent mechanism of signal transduction by the amyloid precursor protein. J Biol Chem 2005, 280:36895-904.

40. Ramelot TA, Gentile LN, Nicholson LK: Transient structure of the amyloid precursor protein cytoplasmic tail indicates preordering of structure for binding to cytosolic factors. Biochemistry 2000, 39:2714-25

41. Ramelot TA, Nicholson LK: Phosphorylation-induced structural changes in the amyloid precursor protein cytoplasmic tail detected by NMR. $J \mathrm{Mol}$ Biol 2001, 307:871-84.

42. He G, Luo W, Li P, Remmers C, Netzer WJ, Hendrick J, Bettayeb K, Flajolet M, Gorelick F, Wennogle LP, Greengard P: Gamma-secretase activating protein is a therapeutic target for Alzheimer's disease. Nature 2010, 467:95-8.

43. Qi-Takahara Y, Morishima-Kawashima M, Tanimura Y, Dolios G, Hirotani N, Horikoshi Y, Kametani F, Maeda M, Saido TC, Wang R, Ihara Y: Longer forms 
of amyloid beta protein: implications for the mechanism of intramembrane cleavage by gamma-secretase. J Neurosci 2005, 25:436-45.

44. Takami M, Nagashima Y, Sano Y, Ishihara S, Morishima-Kawashima M,

Funamoto S, Ihara Y: gamma-Secretase: successive tripeptide and tetrapeptide release from the transmembrane domain of beta-carboxyl terminal fragment. J Neurosci 2009, 29:13042-52.

45. Kornilova AY, Bihel F, Das C, Wolfe MS: The initial substrate-binding site of gamma-secretase is located on presenilin near the active site. Proc Natl Acad Sci USA 2005, 102:3230-5.

46. Herreman A, Serneels L, Annaert W, Collen D, Schoonjans L, De Strooper B: Total inactivation of gamma-secretase activity in presenilin-deficient embryonic stem cells. Nat Cell Biol 2000, 2:461-2.

doi:10.1186/1750-1326-6-15

Cite this article as: Uemura et al: Reciprocal relationship between APP positioning relative to the membrane and PS1 conformation. Molecular Neurodegeneration 2011 6:15

\section{Submit your next manuscript to BioMed Central} and take full advantage of:

- Convenient online submission

- Thorough peer review

- No space constraints or color figure charges

- Immediate publication on acceptance

- Inclusion in PubMed, CAS, Scopus and Google Scholar

- Research which is freely available for redistribution

Submit your manuscript at www.biomedcentral.com/submit
C Biomed Central 